\title{
Prognostic risk classification for biochemical relapse-free survival in patients with oligorecurrent prostate cancer after $\left[{ }^{68} \mathrm{Ga}\right]$ PSMA-PET-guided metastasis-directed therapy
}

\author{
Marco M. E. Vogel ${ }^{1,2}$ (D) - Stephanie G. C. Kroeze ${ }^{3}$ (D) Christoph Henkenberens $^{4}$ (D) $\cdot$ \\ Nina-Sophie Schmidt-Hegemann ${ }^{5}$ (D) - Simon Kirste ${ }^{6,7}$ (D) $\cdot$ Jessica Becker ${ }^{8} \cdot$ Irene A. Burger ${ }^{9}$ (D) Thorsten Derlin $^{10}$ (1) .

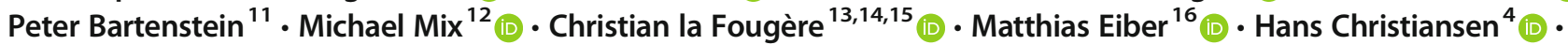

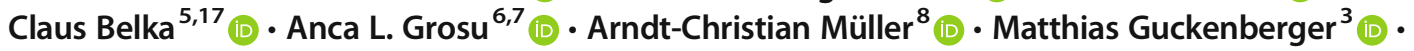 \\ Stephanie E. Combs ${ }^{1,2,17}$
}

Received: 25 November 2019 / Accepted: 4 March 2020 / Published online: 16 March 2020

(C) The Author(s) 2020

\section{Abstract}

Purpose Since the success of prostate-specific membrane antigen-positron emission tomography (PSMA-PET) imaging for patients with oligorecurrent prostate cancer (ORPC), it is increasingly used for radiotherapy as metastasis-directed therapy (MDT). Therefore, we developed a prognostic risk classification for biochemical relapse-free survival (bRFS) for patients after PSMA-PET-guided MDT after radical prostatectomy.

Methods We analyzed 292 patients with local recurrence (LR) and/or pelvic lymph node (LN) lesions and/or up to five distant $\mathrm{LN}$, bone (BM), or visceral metastases (VM) detected with $\left[{ }^{68} \mathrm{Ga}\right]$ PSMA-PET imaging. Median follow-up was 16 months (range $0-57)$. The primary endpoint was bRFS after MDT. Cox regression analysis for risk factors was incorporated into a recursive partitioning analysis (RPA) with classification and regression tree method.

This article is part of the Topical Collection on Oncology - Genitourinary

Marco M. E. Vogel

marco.vogel@tum.de

Stephanie G. C. Kroeze

stephanie.Kroeze@usz.ch

Christoph Henkenberens

henkenberens.christoph@mh-hannover.de

Nina-Sophie Schmidt-Hegemann

Nina-Sophie.Hegemann@med.uni-muenchen.de

Simon Kirste

simon.kirste@uniklinik-freiburg.de

Jessica Becker

jessica.becker@student.uni-tuebingen.de

Irene A. Burger

irene.burger@usz.ch

Thorsten Derlin

derlin.thorsten@mh-hannover.de

Peter Bartenstein

Peter.Bartenstein@med.uni-muenchen.de
Michael Mix

michael.mix@uniklinik-freiburg.de

Christian la Fougère

christian.lafougere@med.uni-tuebingen.de

Matthias Eiber

matthias.eiber@tum.de

Hans Christiansen

christiansen.hans@mh-hannover.de

Claus Belka

Claus.Belka@med.uni-muenchen.de

Anca L. Grosu

anca.grosu@uniklinik-freiburg.de

Arndt-Christian Müller

arndt-christian.mueller@med.uni-tuebingen.de

Matthias Guckenberger

Matthias.Guckenberger@usz.ch

Stephanie E. Combs

stephanie.combs@tum.de

Extended author information available on the last page of the article 
Results PSA at recurrence $\geq 0.8 \mathrm{ng} / \mathrm{mL}, \mathrm{BM}$, and VM was significantly associated with biochemical relapse. RPA showed five groups with tenfold cross-validation of 0.294 (SE 0.032). After building risk classes I to IV $(p<0.0001)$, mean bRFS was 36.3 months (95\% CI 32.4-40.1) in class I (PSA $<0.8 \mathrm{ng} / \mathrm{mL}$, no BM) and 25.8 months (95\% CI 22.5-29.1) in class II (PSA $\geq 0.8 \mathrm{ng} / \mathrm{mL}$, no BM, no VM). LR and/or pelvic LNs caused relapse in classes I and II. Mean bRFS was 16.0 months (95\% CI 12.4-19.6) in class III (PSA irrelevant, present BM) and 5.7 months (95\% CI 2.7-8.7) in class IV (PSA $\geq 0.8 \mathrm{ng} / \mathrm{mL}$, no BM, present VM).

Conclusion We developed and internally validated a risk classification for bRFS after PSMA-PET-guided MDT. Patients with PSA $<0.8 \mathrm{ng} / \mathrm{mL}$ and local relapse only (LR and/or pelvic LNs) had the most promising bRFS. PSA $\geq 0.8 \mathrm{ng} / \mathrm{mL}$ and local relapse only (LR and/or pelvic LNs) indicated intermediate risk for failure. Patients with BM were at higher risk regardless of the PSA. However, those patients still show satisfactory bRFS. In patients with VM, bRFS is heavily decreased. MDT in such cases should be discussed individually.

Keywords Prostate-specific membrane antigen-positron emission tomography · Prostatic carcinoma Oligometastatic . Oligorecurrent · MDT

\section{Introduction}

In 1995, Weichselbaum et al. hypothesized that an oligometastatic state in cancer progression exists [1]. On that basis, the oligorecurrent paradigm was also introduced into prostate cancer (PC) management. However, several descriptions of oligometastatic PC exist, and definitions vary between less than three to five distant lesions [2]. Data show a better outcome for patients with oligometastatic PC than for patients with advanced metastatic disease [3]. Recently, Ost et al. demonstrated that patients with oligorecurrent PC treated with metastasis-directed therapy (MDT) had improved freedom from androgen deprivation therapy (ADT) (13 vs. 21 months) [4]. Furthermore, Decaestecker et al. reported a prolonged time to ADT and no grade III toxicity after repeated stereotactic body radiotherapy (SBRT) [5]. Interestingly, even by using less sensitive choline positron emission tomography (PET) imaging for staging in the trials mentioned above $[4,5]$, a good response to MDT was observed.

Nevertheless, standard-of-care treatment for oligorecurrent PC remains empiric salvage radiotherapy (RT) for suspect local recurrence in the prostatic bed or ADT for patients with distant metastases. Due to limited treatment and diagnostic options, local therapy of the metastatic sites has been rarely used in the past. With the increasing application of prostatespecific membrane antigen (PSMA)-PET imaging, the treatment of patients with few metastases has changed. PSMAPET imaging has become an effective tool for staging and defining targets for precise treatment of patients with biochemical relapse after radical prostatectomy (RP) $[6,7]$. Whereas in the past, radiation oncologists had to administer empiric treatment to the prostate bed mostly without evidence in imaging; today, PSMA-PET helps to visualize recurrent tumor sites and distant lesions and provides a highly sensitive means for estimating the accurate tumor load.

PSMA-PET imaging enriches the possibilities of MDT with conventional fractionated RT, stereotactic body RT
(SBRT), or surgery. These can prolong time to initiation of ADT [2] and bear the possibility of cure.

Up to now, the optimal selection of patients for MDT is unknown. The majority of patients will develop progression, despite PSMA-PET staging and MDT. Therefore, clinical risk classifications have become an accepted instrument for weighing the risk-benefit ratio. To our knowledge, no such tools have been published for patients with oligorecurrent PC treated with MDT using highly sensitive PSMA-targeted imaging. In the present analysis, we aimed to develop a prognostic risk classification predicting biochemical relapse-free survival (bRFS) after PSMA-PET-guided MDT for oligorecurrent prostate cancer after prior RP.

\section{Material and methods}

\section{Patients}

We established a multi-institutional, retrospective database, and collected data of 379 patients from six German and Swiss centers. The institutional review boards of all participating centers approved the study (BASEC-Nr. 2017-01499). The subjects were free from distant metastases (M0) at initial diagnosis. We defined the relapse as biochemical failure and recurrence diagnosed by PSMA-PET imaging. The patients exhibited oligorecurrent disease with local recurrence and/or pelvic lymph node lesions (N1) and/or distant metastases (M1a/1b/1c) in PSMA-PET imaging. We included patients with up to five distant lymph node, bone, or visceral lesions and any PSA level at PSMA-PET-based diagnosis. There was no restriction on the total number of pelvic lymph node lesions. The database included patients treated with MDT for PC metastases independently of the primary therapy. In the present analysis, we included 292 patients with initial RP and a subsequent diagnosis of oligorecurrent $\mathrm{PC}$ with positive findings in PSMA-PET imaging. Patients with other primary 
Fig. 1 Flow diagram of included patients (MDT, metastasisdirected therapy; PC, prostate cancer; RP, radical prostatectomy; $\mathrm{RT}$, radiotherapy)

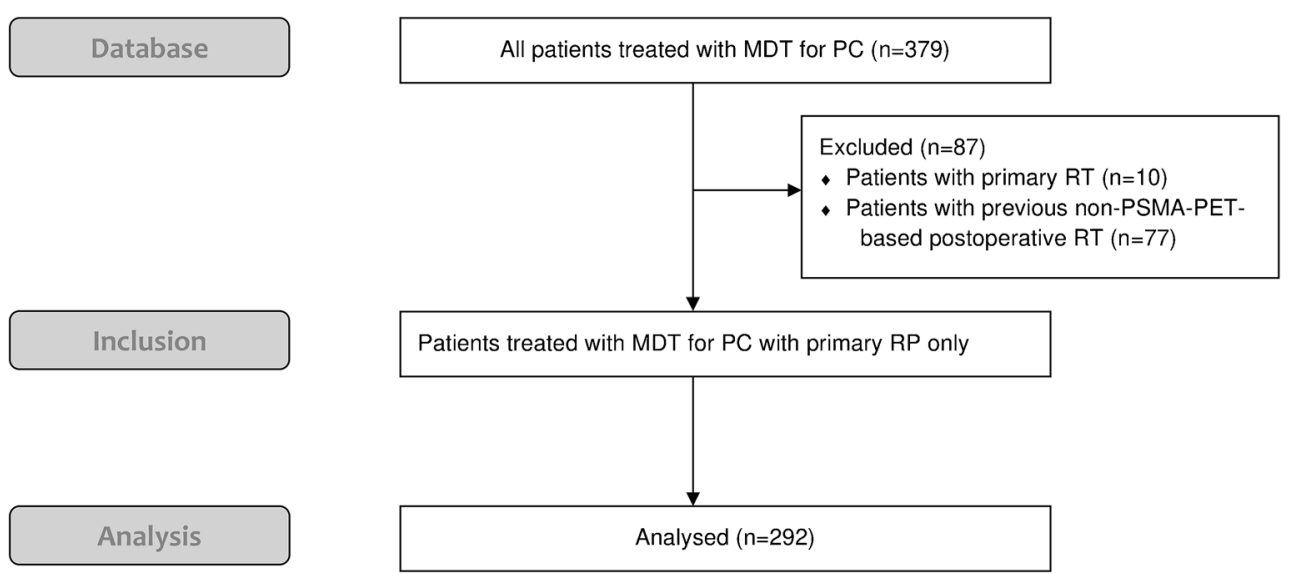

therapy for PC (e.g., primary RT) or with previous postoperative non-PSMA-PET-based RT were exclude from this analysis $(n=87)$. The flow diagram is shown in Fig. 1 .

\section{PSMA-PET imaging and RT}

Each patient received PET imaging with a $\left[{ }^{68} \mathrm{Ga}\right]$-labeled PSMA targeting ligand [8]. Imaging was performed according to the joint EANM and SNMMI guidelines [9]. PSMA-PET imaging was acquired in conjunction with either computed tomography (CT) or magnetic resonance imaging (MRI). The CT was performed as a diagnostic CT or as a low-dose $\mathrm{CT}$. Intravenous and if necessary oral iodinated contrast agents were used if the patients had no contraindications. CT scans were acquired in the portal venous phase. MRI scans where performed with contrast agents, when possible. PET scans were conducted approximately $60 \mathrm{~min}$ after bolus injection of the ligand (mean activity $162.5 \mathrm{MBq}$; range 87.0291.0 MBq). When possible, furosemide $20 \mathrm{mg}$ was given to reduce tracer collection in the urinary tract system. One specialist in nuclear medicine and one radiologist or a dual boarded nuclear medicine physician and radiologist interpreted the acquired imaging. Focal tracer uptake higher than the surrounding background and not associated with physiologic uptake was considered as malignant.

MDT as conventional fractionated RT or SBRT was performed at the discretion of the study centers. Furthermore, ADT was administered according to the guidelines of the participating departments.

\section{Endpoints}

The primary endpoint was bRFS, which was measured from MDT to biochemical relapse. We defined biochemical relapse as PSA levels $\geq 0.2 \mathrm{ng} / \mathrm{mL}$ above PSA nadir after RT. When PSA levels did not respond to RT, pre-RT PSA level with a rise of $\geq 0.2 \mathrm{ng} / \mathrm{mL}$ was defined as a relapse. Follow-up was performed according to institutional protocol.

\section{Statistical analysis}

We applied univariate and multiple Cox regression to assess significance for risk factors for biochemical relapse. We evaluated initial tumor stage [10] (T2c $\leq$ vs. $\geq$ T3a), initial nodal status [11] (N0 vs. N1), initial Gleason score $[10,11](7 \mathrm{a} \leq \mathrm{vs} . \geq 7 \mathrm{~b})$, and initial resection status [11] (R0 vs. R1). Further, we evaluated the risk factors PSA persistence $>0.1 \mathrm{ng} / \mathrm{mL}$ after RP [12], PSA level at PMSA-PET imaging/recurrence $[10,11]$, age at relapse as well as the PSMA-PET-related factors local recurrence (no vs. yes), pelvic lymph node lesions (no vs. yes), distant metastases (no vs. yes), and the number of lesions at PSMA-PET imaging. We used receiver operating characteristic (ROC) analysis to determine cutoff values for non-dichotomous variables. To account for the possible confounder of additive ADT administration and to show robustness of the model, multiple Cox regression was calculated unadjusted and adjusted for additive ADT. Risk factors which showed significance in both models were included into the risk classification. We used recursive partitioning analysis (RPA) with the classification and regression tree (CRT) method to analyze the significant factors. bRFS at 12 months was the primary endpoint in the decision tree calculation. Decision tree analysis is a nonparametric automatic statistical learning algorithm that combines variables. The results are shown in a decision tree with splits based on the variables. The Gini index was applied to minimize node impurity after splitting. End nodes of the decision tree were grouped from A to E. For internal validation, we used tenfold cross-validation. In the tenfold cross-validation scheme, patients were randomly assigned into ten equal subgroups. Nine subsets were utilized as a training cohort. The tenth group was used as a validation set to test the performance. Subsequently, risk classes I to IV (low to very high risk) were built by combining end node groups with a similar outcome in Kaplan-Meier estimator for the overall group. We used the Kaplan-Meier method to calculate bRFS of the risk classes. All statistical analyses were performed 
with SPSS version 21 (IBM, Armonk, USA). A $p$ value of less than 0.05 was defined as statistically significant.

\section{Results}

All patients were treated for oligorecurrent PC with conventional fractionated RT and/or SBRT between April 2013 and January 2018. The median age of all patients was 70 years (range 4695 years). Median follow-up was 16 months (range $0-57$ months). Table 1 shows the patient characteristics, and Table 2 shows the numbers of biochemical relapse and local control.

Table 3 shows the results of the univariate Cox regression of prognostic factors affecting bRFS. ROC analysis determined $0.8 \mathrm{ng} / \mathrm{mL}$ as the significant cutoff value for PSA before RT. A PSA persistence after RP $\geq 0.1 \mathrm{ng} / \mathrm{mL}$, PSA levels prior to RT $\geq 0.8 \mathrm{ng} / \mathrm{mL}$, the presence of bone metastases, and the presence of visceral lesions were significantly associated with relapse in the univariate analysis. Multiple Cox regression unadjusted and adjusted for additive ADT is shown in Table 4. PSA levels $\geq 0.8 \mathrm{ng} / \mathrm{mL}$, the presence of bone metastases, and the presence of visceral metastases remained significant factors in both models.

We included the three significant factors of both models into the RPA using the CRT method. Figure 2 shows the decision tree with the end nodes A to E. Tenfold crossvalidation demonstrated a risk for miscalculation of 0.294 (standard error 0.032 ), which results in $70.6 \%$ accuracy.

The Kaplan-Meier estimator showed a mean bRFS of 36.3 months (95\% CI 32.4 40.1 months) for group A (PSA < $0.8 \mathrm{ng} / \mathrm{mL}$, no bone lesions), of 25.8 months (95\% CI 22.529.1 months) for group $\mathrm{B}$ (PSA $\geq 0.8 \mathrm{ng} / \mathrm{mL}$, no bone or visceral lesions), of 15.6 months (95\% CI 11.3-20.0 months) for group $\mathrm{C}$ (PSA $<0.8 \mathrm{ng} / \mathrm{mL}$, present bone lesions), of 16.6 months (95\% CI 11.2-22.0 months) for group D (PSA $\geq 0.8 \mathrm{ng} / \mathrm{mL}$, present bone lesions), and of 5.7 months (95\% CI 2.78.7 months) for group $\mathrm{E}$ (PSA $\geq 0.8 \mathrm{ng} / \mathrm{mL}$, no bone lesions, present visceral lesions). Subsequently, we built risk classes with a similar outcome: risk class I with low risk (group A), class II with intermediate risk (group B), class III with high risk (groups C and D), and class IV with very high risk (group E). We used the Kaplan-Meier estimator to compare survival among risk classes for the overall group (see Fig. 3). The log-rank test showed significant differences among groups with $p<0.0001$.

The risk classification showed that patients with PSA levels $<0.8 \mathrm{ng} / \mathrm{mL}$ and no bone metastases according to PSMA-PET experience low risk (class I). Patients diagnosed with PSA levels $\geq 0.8 \mathrm{ng} / \mathrm{mL}$ and no bone metastases nor visceral metastases prior to MDT were at intermediate risk (class II). PSMA-PET-positive local recurrence and/or pelvic lymph node lesions caused the PSA rise in those two classes. Patients with bone metastases before MDT independently of
Table 1 Patient characteristics $(n=292)$

All patients

$(n=292) n(\%)$

\begin{tabular}{|c|c|}
\hline \multicolumn{2}{|l|}{ Initial tumor classification } \\
\hline pT1c & $1(0.3 \%)$ \\
\hline pT2a & $9(3.1 \%)$ \\
\hline pT2b & $10(3.4 \%)$ \\
\hline pT2c & $96(32.9 \%)$ \\
\hline pT3a & $71(24.3 \%)$ \\
\hline pT3b & $96(32.9 \%)$ \\
\hline pT4 & $9(3.1 \%)$ \\
\hline \multicolumn{2}{|l|}{ Initial nodal status } \\
\hline Negative & $185(63.4 \%)$ \\
\hline Positive & $95(32.5 \%)$ \\
\hline Missing & $12(4.1 \%)$ \\
\hline \multicolumn{2}{|l|}{ Gleason score } \\
\hline 6 & $16(5.5 \%)$ \\
\hline $7 \mathrm{a}$ & $67(22.9 \%)$ \\
\hline $7 \mathrm{~b}$ & $86(29.5 \%)$ \\
\hline$\geq 8$ & $123(42.1 \%)$ \\
\hline \multicolumn{2}{|l|}{ Surgical margin } \\
\hline Negative & $161(55.1 \%)$ \\
\hline Positive & $131(44.9 \%)$ \\
\hline \multicolumn{2}{|c|}{ Parameters at PSMA-PET-based diagnosis of oligorecurrent disease } \\
\hline Median age at PSMA-PET imaging (years) & 70 (range 46-95) \\
\hline $\begin{array}{l}\text { Median PSA level at PSMA-PET imaging } \\
(\mathrm{ng} / \mathrm{mL})\end{array}$ & 0.95 (range $0.04-40.13$ ) \\
\hline \multicolumn{2}{|l|}{ Local recurrence at PSMA-PET imaging } \\
\hline No & $163(55.8 \%)$ \\
\hline Yes & $129(44.2 \%)$ \\
\hline \multicolumn{2}{|l|}{ Pelvic lymph node metastases at PSMA-PET imaging } \\
\hline Negative & $135(46.2 \%)$ \\
\hline Positive & $157(53.8 \%)$ \\
\hline \multirow{2}{*}{\multicolumn{2}{|c|}{ Distant metastases at PSMA-PET imaging }} \\
\hline Lymph nodes (M1a) & \\
\hline No & $267(91.4 \%)$ \\
\hline Yes & $25(8.6 \%)$ \\
\hline \multicolumn{2}{|l|}{ Bone (M1b) } \\
\hline No & $247(84.6 \%)$ \\
\hline Yes & $45(15.4 \%)$ \\
\hline \multicolumn{2}{|l|}{ Visceral (M1c) } \\
\hline No & $289(99.0 \%)$ \\
\hline Yes & $3(1.0 \%)$ \\
\hline Median total number of PET-positive lesions & 1 (range $1-19$ ) \\
\hline Pelvic lymph node lesions & 1 (range $1-19)$ \\
\hline Distant metastases & 1 (range $1-5$ ) \\
\hline \multicolumn{2}{|l|}{ RT Technique } \\
\hline Conventional fractionated RT & $265(90.8 \%)$ \\
\hline SBRT & $17(5.8 \%)$ \\
\hline Conventional fractionated RT + SBRT & $10(3.4 \%)$ \\
\hline \multicolumn{2}{|c|}{ Elective RT to prostate bed or locoregional lymph nodes } \\
\hline No & $72(24.7 \%)$ \\
\hline Yes & $220(75.3 \%)$ \\
\hline \multicolumn{2}{|l|}{ Median EQD2/1.5 Gy (Gy) } \\
\hline Prostatic fossa & 66.0 (range $47.5-70.0)$ \\
\hline Pelvic lymphatic pathways & 47.5 (range $42.0-56.0$ ) \\
\hline PET-positive local recurrence & 70.0 (range $57.7-83.0$ ) \\
\hline PET-positive lymph nodes & 60.0 (range $46.0-85.0$ ) \\
\hline Bone lesions & 56.0 (range $40.0-108.6$ \\
\hline Visceral lesions & $\begin{array}{l}108.6(\text { range } \\
103.0-162.0)\end{array}$ \\
\hline \multicolumn{2}{|l|}{ Additive ADT } \\
\hline No & $178(61.0 \%)$ \\
\hline Yes & $114(39.0 \%)$ \\
\hline Median follow-up (months) & 16 (range: $0-57$ ) \\
\hline
\end{tabular}

PSMA-PET, prostate-specific membrane antigen-positron emission tomography; $P S A$, prostate-specific antigen; $R T$, radiotherapy; $S B R T$, stereotactic body radiotherapy; $E Q D 2 / 1.5 G y$, equivalent dose in 2 Gy for alpha/beta of $1.5 \mathrm{~Gy} ; A D T$, androgen deprivation therapy 
Table 2 Number of biochemical relapse and in-field local control

\begin{tabular}{ll}
\hline Biochemical relapse & \\
\hline Biochemical relapse at 12 months & \\
Yes & $19.5 \%(57 / 292)$ \\
No & $47.9 \%(140 / 292)$ \\
No information & $2.1 \%(6 / 292)$ \\
Censored & $30.5 \%(89 / 292)$ \\
Overall biochemical relapse & \\
Yes & $29.8 \%(87 / 292)$ \\
No & $68.1 \%(199 / 292)$ \\
No information & $2.1 \%(6 / 292)$ \\
In-field local control & \\
Local recurrence & $96.4 \%(53 / 55)$, missing information on 40 lesions \\
Pelvic lymph nodes & $96.0 \%(145 / 151)$, missing information on 48 lesions \\
Bone lesions & $100 \%(32 / 32)$, missing information on nine lesions \\
Visceral lesions & $100 \%(2 / 2)$, missing information on one lesion \\
\hline
\end{tabular}

Patients with missing information on lesions received no imaging due to no biochemical relapse the PSA value showed a faster relapse (class III). Patients with a PSA level $\geq 0.8 \mathrm{ng} / \mathrm{mL}$, no bone metastases, and the presence of visceral metastases were at very high risk for decreased bRFS (class IV). Table 5 shows the risk classes with the respective bRFS and a description of the prognostic factors. Distribution, duration, and medication of additive ADT use in the risk classes are shown in Table 6.

\section{Discussion}

The present analysis aimed to develop a prognostic risk classification for bRFS after PSMA-PET-guided MDT for patients with oligorecurrent PC. Three variables emerged as prognostic factors for decreased bRFS in multiple Cox regression: PSA level $\geq$ $0.8 \mathrm{ng} / \mathrm{mL}$, presence of bone metastases and visceral lesions.
Table 3 Univariate Cox regression of prognostic factors for biochemical relapse

\begin{tabular}{llll}
\hline Factors & \multicolumn{2}{l}{ Univariate Cox regression } \\
\cline { 2 - 4 } & HR & $95 \%$ CI & $p$ \\
\hline Initial tumor stage (T2c $\leq$ vs. $\geq$ T3a) & 0.67 & $0.43-1.05$ & 0.08 \\
Initial nodal status (N0 vs. N1) & 0.67 & $0.43-1.05$ & 0.08 \\
Initial Gleason score (7a $\leq$ vs. $\geq 7 \mathrm{~b})$ & 0.66 & $0.39-1.08$ & 0.10 \\
Initial resection status (R0 vs. R1) & 1.02 & $0.67-1.58$ & 0.91 \\
PSA persistence $>0.1$ ng/mL after RP (yes vs. no) & 1.59 & $1.04-2.43$ & $0.03^{*}$ \\
PSA level at PMSA-PET imaging (>0.8 ng/mL vs. $\leq 0.8$ ng/mL) & 0.51 & $0.32-0.79$ & $0.003^{*}$ \\
Age at relapse (continuous) & 1.00 & $0.98-1.03$ & 0.90 \\
Local recurrence at PSMA-PET imaging (no vs. yes) & 1.46 & $0.95-2.26$ & 0.09 \\
Pelvic lymph node lesions at PSMA-PET imaging (no vs. yes) & 1.05 & $0.69-1.60$ & 0.82 \\
Distant metastases at PSMA-PET imaging & & & \\
$\quad$ Lymph nodes (no vs. yes) & 0.80 & $0.40-1.60$ & 0.53 \\
$\quad$ Bone (no vs. yes) & 0.38 & $0.24-0.62$ & $0.0001^{*}$ \\
$\quad$ Visceral (no vs. yes) & 0.19 & $0.05-0.78$ & $0.02^{*}$ \\
Total number of lesions (1 versus $>1$ ) & 0.96 & $0.58-1.59$ & 0.87 \\
Use of additive ADT & 2.56 & $1.51-4.36$ & $0.0005^{*}$ \\
\hline PSA
\end{tabular}

$P S A$, prostate-specific antigen; $R P$, radical prostatectomy; $P S M A-P E T$, prostate-specific membrane antigen-positron emission tomography; $A D T$, androgen deprivation therapy; $H R$, hazard ratio; $95 \% C I, 95 \%$ confidence interval

*Significant result 
Table 4 Multiple Cox regression of prognostic factors for biochemical relapse unadjusted and adjusted for additive androgen deprivation therapy

\begin{tabular}{|c|c|c|c|c|c|c|}
\hline \multirow[t]{2}{*}{ Factors } & \multicolumn{3}{|c|}{$\begin{array}{l}\text { Multiple Cox regression } \\
\text { unadjusted for ADT }\end{array}$} & \multicolumn{3}{|c|}{$\begin{array}{l}\text { Multiple Cox regression } \\
\text { adjusted for ADT }\end{array}$} \\
\hline & $\mathrm{HR}$ & $95 \% \mathrm{CI}$ & $p$ & $\mathrm{HR}$ & $95 \% \mathrm{CI}$ & $p$ \\
\hline $\begin{array}{l}\text { PSA } \\
\text { persistence } \\
>0.1 \mathrm{ng} /- \\
\text { mL after } \\
\text { RP (yes vs. } \\
\text { no) }\end{array}$ & 1.51 & $0.98-2.35$ & 0.07 & 1.78 & $1.14-2.77$ & $0.011 *$ \\
\hline $\begin{array}{l}\text { PSA level at } \\
\text { PMSA-PE- } \\
\text { T imaging } \\
\text { (>0.8 ng/- } \\
\text { mL vs. }\end{array}$ & & & & & & \\
\hline
\end{tabular}

$\leq 0.8 \mathrm{ng} / \mathrm{mL}$ )舄0.62鳥0.39-0.98g鳥 $0.04 *$

0.50

$0.31-0.79$

0.003 䳔Distant bone metastases at PSMA-PET imaging (no vs. yes)舄 0.39 䲯 $0.24-0.64$ 舄 $0.0002 *$

2.17

$1.33-3.56$

0.002 寫Distant visceral metastases at PSMA-PET imaging (no vs. yes)舄 0.09 舄 $0.02-0.38$ 舄 0.001 *

7.65

$1.75-33.44$

0.007 獡Use of additive ADT舄

3.24

$1.87-5.60$

$0.00002 * P S A$, prostate-specific antigen; $R P$, radical prostatectomy; PSMA-PET, prostate-specific membrane antigen-positron emission tomography; $A D T$, androgen deprivation therapy; $H R$, hazard ratio; $95 \%$ $C I, 95 \%$ confidence interval

*Significant result

With these results, we built a risk classification which showed a convincing internal tenfold cross-validation with $70.6 \%$ accuracy.

Recently, few retrospective series with small patient cohorts have demonstrated the feasibility and efficacy of PSMA-PET-guided RT and SBRT [6, 13-18]. Siva et al. prospectively analyzed 33 patients and showed that MDT is a feasible treatment option [19]. In the recent STOMP phase II trial, Ost et al. demonstrated prolonged freedom from ADT with MDT [4]. However, both prospective trials did not use modern PSMA-PET imaging for staging. To our knowledge, the present study is the largest retrospective analysis with patients suffering from oligorecurrent PC treated with PSMAPET-guided MDT.

Our classification shows that patients with low PSA levels $(<0.8 \mathrm{ng} / \mathrm{mL})$ and pelvic lymph node lesions and/or local recurrence only benefit the most from PSMA-PET-guided MDT (class I). Patients with PSA level $\geq 0.8 \mathrm{ng} / \mathrm{mL}$ and pelvic lymph node lesions and/or local recurrence only are at intermediate risk for treatment failure (class II). Hence, our data show a favorable outcome for patients treated with PSMA-PET-guided MDT who are diagnosed with local relapse only. Recently, Schmidt-Hegemann et al. reported a good response to PSMA-PET-guided salvage RT. The authors showed a bRFS of $78 \%$ after a median follow-up of 23 months for patients with local relapse only [20]. Furthermore, early treatment of oligorecurrent PC at low PSA levels is desirable. It remains not surprising that the PSA level before MDT is a prognostic factor for biochemical relapse. For local salvage RT, the dictum shifted to "the earlier, the better." Several studies have shown that a high pre-treatment PSA level before local salvage RT is associated with a decreased biochemical and oncological outcome [21-24]. Early salvage treatment should be initiated at PSA levels of less than $0.5 \mathrm{ng} / \mathrm{mL}$ [11]. However, data on the prognostic value of pre-PSA level before MDT in patients with oligorecurrent PC remains rare. Our data showed a pre-treatment PSA level of $0.8 \mathrm{ng} / \mathrm{mL}$ as the cutoff value. Although this value seems high, treatment of oligorecurrent PC appears to be beneficial when administered in patients with PSA levels $<0.8 \mathrm{ng} / \mathrm{mL}$ or preferably earlier.

Patients with present bone metastases were at higher risk for biochemical relapse (class III). However, those patients still show satisfactory bRFS. Bone metastases are common in patients with metastatic PC [25]. Muacevic et al. reported a local control rate of $95.5 \%$ at 24 months in patients treated with robotic SBRT for bone metastases [26]. In a previous study, Habl et al. showed a local progression-free survival (PFS) of $100 \%$ at 24 months for patients with bone lesions treated with SBRT. However, the median PSA-PFS was 6.9 months, and the median distant PFS was only 7.4 months [6]. In our study, in-field local control of bone lesions was $100 \%$; bRFS of patients with bone lesions was 16.0 months. The limited effectiveness in systemic control in the series of Habl et al. might be owed to the inability to detect all present metastatic lesions [6] since the authors staged the patients with PET imaging using either the $\left[{ }^{68} \mathrm{Ga}\right] \mathrm{PSMA}$ or the $\left[{ }^{11} \mathrm{C}\right]$ choline tracer. Therefore, the less sensitive choline-PET imaging might not have detected all lesions. Although PSMA-PET imaging shows a massive improvement in sensitivity at low PSA levels as compared with choline-PET, the detection rate of recurrences is still approximately $50 \%$ at PSA levels below $0.2 \mathrm{ng} / \mathrm{mL}$ [27]. Perera et al. reported rates of $58 \%$ and $76 \%$ for PSA levels of $0.2-1.0$ and $1.0-2.0 \mathrm{ng} / \mathrm{mL}$ for PET scans with $\left[{ }^{68} \mathrm{Ga}\right]$ PSMA tracers [28]. The optimal threshold value of PSA indicating a high chance of detection of tumor relapse in PSMA-PET imaging remains a topic of discussion.

Patients with visceral metastases experience heavily reduced bRFS (class IV). Although visceral metastases are not common in patients with prostate cancer [25], survival is decreased in general. Gandaglia et al. reported a reduced median overall survival (OS) and PC-specific survival (PSS) in patients with visceral metastases (median OS 16 months, median PSS 26 months) [25]. Only patients with synchronous bone 
Fig. 2 Recursive partitioning analysis (RPA) with the classification and regression tree (CRT) method ( $n=197$, data of 95 patients was censored at 12 months). End nodes are marked with groups A to E. (PSMA-PET, prostate-specific membrane antigen-positron emission tomography; PSA, prostate-specific antigen; $\mathrm{ng} / \mathrm{mL}$, nanogram/milliliter)

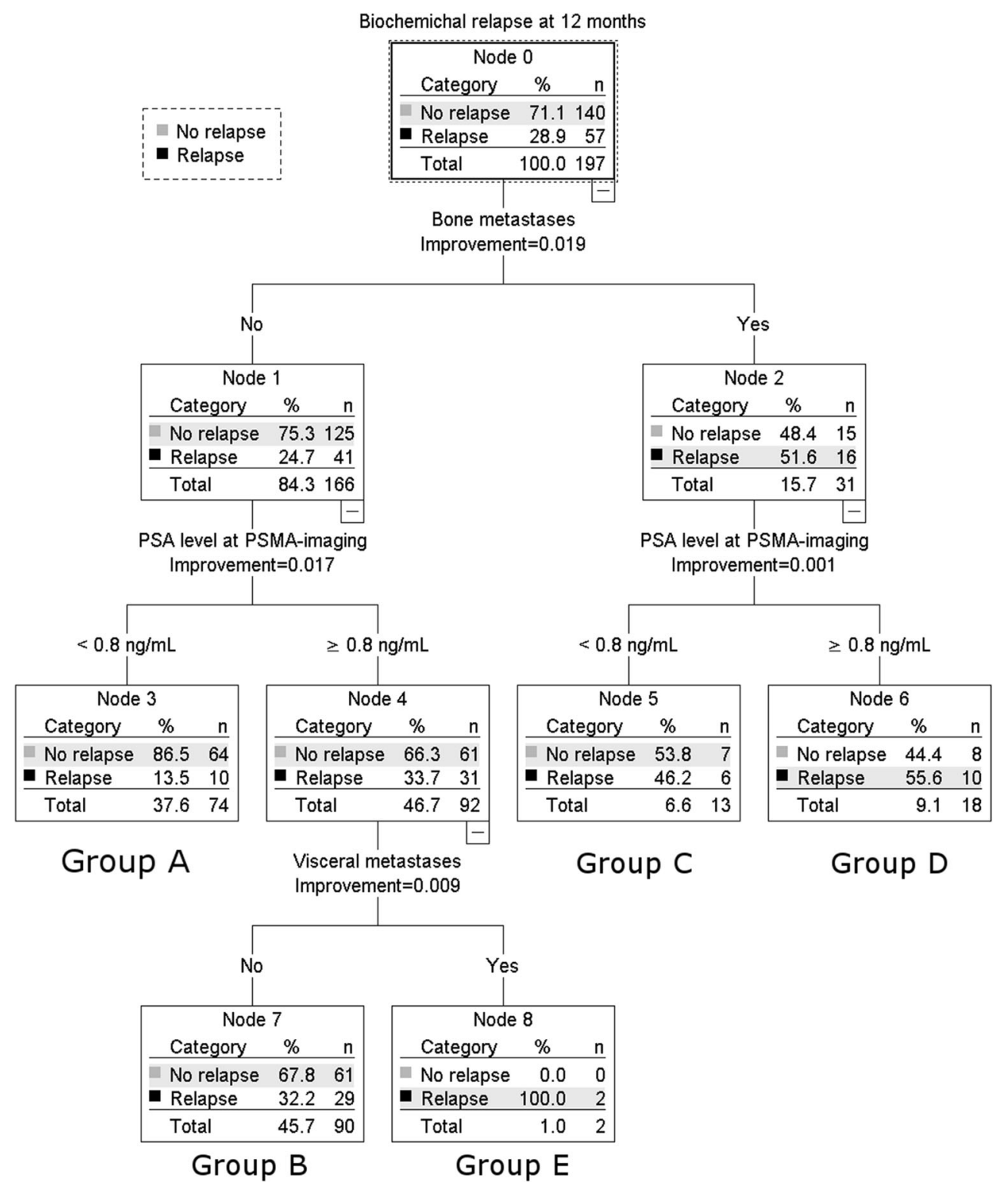

and visceral metastases showed a worse result (median OS 14 months, median PSS 19 months) [29]. The reduced outcome was a reason for defining visceral metastases as highvolume or high-risk disease in the CHAARTED [30] and LATITUDE [31] trial. The data on MDT for patients with visceral metastases is still limited. Ost et al. showed no difference in outcome after MDT between patients with nodal versus non-nodal metastases as visceral lesions [4]. However, the study recruited only one patient with visceral lesions. Although we evaluated a good in-field local control of $100 \%$ in patients with visceral metastases, the systemic effect seemed suboptimal. Patients developed biochemical relapse rapidly after local treatment. Therefore, patients with visceral lesions might exhibit a different, more aggressive tumor biology than patients with bone or lymph node metastases. Such patients might benefit from additional ADT to MDT [32].
However, in such cases, MDT should be discussed individually. Bearing in mind the reduced bRFS, palliative ADT alone might be a valid alternative.

Our study has certain limitations. Because of the retrospective nature, the management in terms of treatment was not prospectively defined and differed between institutions. Administration of additive ADT was not standardized and might be a confounder. To account for this problem, we calculated a multiple Cox regression unadjusted and adjusted for additive ADT to show robustness of the model. Furthermore, RT technique and treatment differed between institutions with conventional RT on the one hand to extreme hypofractionated schedules for distant metastasis on the other hand. This must be considered when interpreting the results. However, all visible lesions and thus all the tumor burden was treated with good in- 
Fig. 3 Kaplan-Meier estimator for biochemical relapse-free survival time in months stratified for risk classes I to IV for the overall group

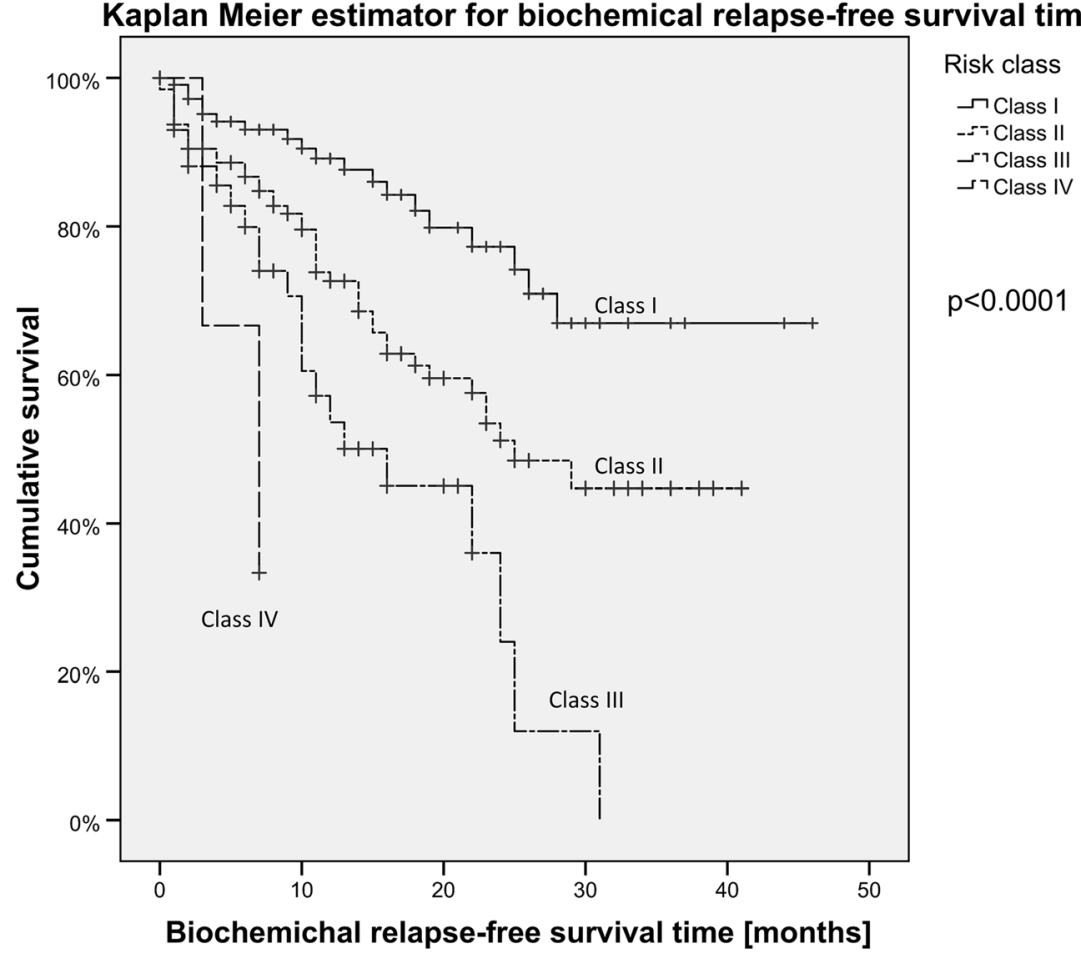

\begin{tabular}{lllllll} 
Class I & 110 & 71 & 32 & 12 & 2 & 0 \\
Class II & 130 & 76 & 32 & 12 & 1 & 0 \\
Class III & 44 & 21 & 8 & 1 & 0 & 0 \\
Class IV & 3 & 0 & 0 & 0 & 0 & 0 \\
& \multicolumn{7}{c}{ Number at risk }
\end{tabular}

field local control (see Table 2). Therefore, influence on bRFS should be low. The group of patients with visceral metastases was small. Therefore, the results must be interpreted with caution. However, the findings are plausible as several studies show the poor outcome of patients with visceral lesions. The results will be validated externally for further evidence.

Table 5 Risk classes for bRFS after PSMA-PET-guided RT

\begin{tabular}{|c|c|c|c|c|}
\hline Risk class & RPA group & $\begin{array}{l}\text { Mean bRFS } \\
(95 \% \mathrm{CI}) \text { in months }\end{array}$ & $\begin{array}{l}\text { Median bRFS } \\
(95 \% \mathrm{CI}) \text { in months }\end{array}$ & Risk class characteristics \\
\hline Class I (low risk) & Group A & $36.3(32.4-40.1)$ & Not reached & $\begin{array}{l}\text { PSA level at PSMA-PET imaging } \\
<0.8 \mathrm{ng} / \mathrm{mL} \text {, no bone metastases, present } \\
\text { local recurrence, and/or pelvic lymph } \\
\text { nodes only }\end{array}$ \\
\hline Class II (intermediate risk) & Group B & $25.8(22.5-29.1)$ & $25.0(18.3-31.7)$ & $\begin{array}{l}\text { PSA level at PSMA-PET imaging } \\
\geq 0.8 \mathrm{ng} / \mathrm{mL} \text {, no bone metastases, no } \\
\text { visceral metastases, present local } \\
\text { recurrence, and/or pelvic lymph nodes only }\end{array}$ \\
\hline \multirow[t]{2}{*}{ Class III (high risk) } & Group C & $16.0(12.4-19.6)$ & $16.0(6.5-25.5)$ & $\begin{array}{l}\text { PSA level at PSMA-PET imaging } \\
<0.8 \mathrm{ng} / \mathrm{mL} \text {, present bone metastases }\end{array}$ \\
\hline & Group D & & & $\begin{array}{l}\text { PSA level at PSMA-PET imaging } \\
\geq 0.8 \mathrm{ng} / \mathrm{mL} \text {, present bone metastases }\end{array}$ \\
\hline Class IV (very high risk) & Group E & $5.7(2.7-8.7)$ & $7.0(0.6-13.4)$ & $\begin{array}{l}\text { PSA level at PSMA-PET imaging } \\
\geq 0.8 \mathrm{ng} / \mathrm{mL} \text {, no bone metastases, present } \\
\text { visceral metastases }\end{array}$ \\
\hline
\end{tabular}

$b R F S$, biochemical relapse-free survival; PSMA-PET, prostate-specific membrane antigen-positron emission tomography; $P S A$, prostate-specific antigen; $R P A$, recursive partitioning analysis 
Table 6 Additive androgen deprivation therapy (ADT) in risk classes

\begin{tabular}{lccc}
\hline Risk class & Use of $\operatorname{ADT}(n, \%)$ & Median duration of ADT & ADT medication $(n, \%)$ \\
\hline Class I (low risk) & $31(27.9)$ & 8 months (range 2-30 months) & $\begin{array}{l}\text { LHRH agonist, 18 (58.1) } \\
\text { Antiandrogen, 10 (32.3) } \\
\text { Unknown, 3 (9.6) }\end{array}$ \\
Class II (intermediate risk) & $68(51.1)$ & 6 months (range 1-34 months) & $\begin{array}{l}\text { LHRH agonist, 40 (58.8) } \\
\text { Antiandrogen, 28 (41.2) }\end{array}$ \\
Class III (high risk) & $14(31.1)$ & 8.5 months (range 2-21 months) & $\begin{array}{l}\text { LHRH agonist, 8 (57.1) } \\
\text { Antiandrogen, 6 (42.9) } \\
\text { Class IV (very high risk) }\end{array}$ \\
& $1(33.3)$ & 11 months (range 11-11 months) & LHRH agonist, 1 (100.0) \\
& & & Antiandrogen, 0 (0.0) \\
\hline
\end{tabular}

$A D T$, androgen deprivation therapy; $L H R H$, luteinizing hormone-releasing hormone

\section{Conclusion}

We developed a prognostic risk classification for biochemical relapse after PSMA-PET-guided MDT after RP with convincing internal validation. This classification might be used to weigh the risk-benefit ratio of local curative RT for oligorecurrent lesions. According to this risk classification, patients with PSA levels $<$ $0.8 \mathrm{ng} / \mathrm{mL}$ and with local relapse only (local recurrence and/or pelvic lymph nodes) had the most promising bRFS after MDT. PSA levels $\geq 0.8 \mathrm{ng} / \mathrm{mL}$ and local relapse only (local recurrence and/or pelvic lymph nodes) indicated intermediate risk for failure. Patients with bone lesions were at higher risk for failure after MDT regardless of the PSA level. However, those patients still show satisfactory bRFS. In patients with visceral metastases, bRFS is heavily decreased; thus, MDT in such cases should be discussed individually.

Author's contribution All authors contributed to the study conception and design. Material preparation and data collection were performed by Marco M. E. Vogel, Stephanie G. C. Kroeze, Christoph Henkenberens, Nina-Sophie Schmidt-Hegemann, Simon Kirste, and Jessica Becker. Analysis was performed by Marco M. E. Vogel and Stephanie E. Combs. The first draft of the manuscript was written by Marco M. E. Vogel and all authors commented on previous versions of the manuscript. All authors read and approved the final manuscript.

Funding Information Open Access funding provided by Projekt DEAL.

\section{Compliance with ethical standards}

Conflict of interest Arnd-Christian Müller declares scientific cooperation with Electa ${ }^{\circledR}$, Philips ${ }^{\circledR}$ and Siemens ${ }^{\circledR}$. Matthias Eiber is consultant for Blue Earth Diagnostics ${ }^{\circledR}$ and $\mathrm{ABX} \bowtie$ and has patent rights on rhPSMA. All other authors have no conflict of interest to declare.

Ethical approval The institutional review boards of all participating centers approved the study (BASEC-Nr. 2017-01499).

Open Access This article is licensed under a Creative Commons Attribution 4.0 International License, which permits use, sharing, adaptation, distribution and reproduction in any medium or format, as long as you give appropriate credit to the original author(s) and the source, provide a link to the Creative Commons licence, and indicate if changes were made. The images or other third party material in this article are included in the article's Creative Commons licence, unless indicated otherwise in a credit line to the material. If material is not included in the article's Creative Commons licence and your intended use is not permitted by statutory regulation or exceeds the permitted use, you will need to obtain permission directly from the copyright holder. To view a copy of this licence, visit http://creativecommons.org/licenses/by/4.0/.

\section{References}

1. Weichselbaum RR, Hellman S. Oligometastases revisited. Nat Rev Clin Oncol. 2011;8(6):378-82. https://doi.org/10.1038/nrclinonc. 2011.44.

2. Ost P, Bossi A, Decaestecker K, De Meerleer G, Giannarini G, Karnes RJ, et al. Metastasis-directed therapy of regional and distant recurrences after curative treatment of prostate cancer: a systematic review of the literature. Eur Urol. 2015;67(5):852-63. https://doi. org/10.1016/j.eururo.2014.09.004.

3. Ost P, Decaestecker K, Lambert B, Fonteyne V, Delrue L, Lumen $\mathrm{N}$, et al. Prognostic factors influencing prostate cancer-specific survival in non-castrate patients with metastatic prostate cancer. Prostate. 2014;74(3):297-305. https://doi.org/10.1002/pros.22750.

4. Ost P, Reynders D, Decaestecker K, Fonteyne V, Lumen N, De Bruycker A, et al. Surveillance or metastasis-directed therapy for oligometastatic prostate cancer recurrence: a prospective, randomized, multicenter phase II trial. J Clin Oncol. 2018;36(5):446-53. https://doi.org/10.1200/jco.2017.75.4853.

5. Decaestecker K, De Meerleer G, Lambert B, Delrue L, Fonteyne V, Claeys $\mathrm{T}$, et al. Repeated stereotactic body radiotherapy for oligometastatic prostate cancer recurrence. Radiat Oncol. 2014;9: 135. https://doi.org/10.1186/1748-717X-9-135.

6. Habl G, Sauter K, Schiller K, Dewes S, Maurer T, Eiber M, et al. (68) Ga-PSMA-PET for radiation treatment planning in prostate cancer recurrences after surgery: individualized medicine or new standard in salvage treatment. Prostate. 2017;77(8):920-7. https:// doi.org/10.1002/pros.23347.

7. Schiller K, Sauter K, Dewes S, Eiber M, Maurer T, Gschwend J, et al. Patterns of failure after radical prostatectomy in prostate cancer - implications for radiation therapy planning after (68)GaPSMA-PET imaging. Eur J Nucl Med Mol Imaging. 2017;44(10): 1656-62. https://doi.org/10.1007/s00259-017-3746-9.

8. Eder M, Schafer M, Bauder-Wust U, Hull WE, Wangler C, Mier W, et al. 68Ga-complex lipophilicity and the targeting property of a urea-based PSMA inhibitor for PET imaging. Bioconjug Chem. 2012;23(4):688-97. https://doi.org/10.1021/bc200279b. 
9. Fendler WP, Eiber M, Beheshti M, Bomanji J, Ceci F, Cho S, et al. (68)Ga-PSMA PET/CT: joint EANM and SNMMI procedure guideline for prostate cancer imaging: version 1.0. Eur J Nucl Med Mol Imaging. 2017;44(6):1014-24. https://doi.org/10.1007/ s00259-017-3670-z.

10. Song W, Jeon HG, Sung HH, Jeong BC, Seo SI, Jeon SS, et al. Prognostic factors after salvage radiotherapy alone in patients with biochemical recurrence after radical prostatectomy. Int J Urol. 2016;23(1):56-61. https://doi.org/10.1111/iju.12960.

11. Stephenson AJ, Scardino PT, Kattan MW, Pisansky TM, Slawin $\mathrm{KM}$, Klein EA, et al. Predicting the outcome of salvage radiation therapy for recurrent prostate cancer after radical prostatectomy. J Clin Oncol. 2007;25(15):2035-41. https://doi.org/10.1200/jco. 2006.08.9607.

12. Bartkowiak D, Siegmann A, Bohmer D, Budach V, Wiegel T. The impact of prostate-specific antigen persistence after radical prostatectomy on the efficacy of salvage radiotherapy in patients with primary N0 prostate cancer. BJU Int. 2019;124(5):785-91. https:// doi.org/10.1111/bju.14851.

13. Bluemel C, Linke F, Herrmann K, Simunovic I, Eiber M, Kestler C, et al. Impact of (68)Ga-PSMA PET/CT on salvage radiotherapy planning in patients with prostate cancer and persisting PSA values or biochemical relapse after prostatectomy. EJNMMI Res. 2016;6(1):78. https://doi.org/10.1186/s13550-016-0233-4.

14. Emmett L, van Leeuwen PJ, Nandurkar R, Scheltema MJ, Cusick T, Hruby G, et al. Treatment outcomes from (68)Ga-PSMA PET/ CT-informed salvage radiation treatment in men with rising PSA after radical prostatectomy: prognostic value of a negative PSMA PET. J Nucl Med. 2017;58(12):1972-6. https://doi.org/10.2967/ jnumed.117.196683.

15. Henkenberens C, von Klot CA, Ross TL, Bengel FM, Wester HJ, Katja H, et al. (68)Ga-PSMA ligand PET/CT-based radiotherapy for lymph node relapse of prostate cancer after primary therapy delays initiation of systemic therapy. Anticancer Res. 2017;37(3): 1273-9. https://doi.org/10.21873/anticanres.11444.

16. Henkenberens C, von Klot CA, Ross TL, Bengel FM, Wester HJ, Merseburger AS, et al. (68)Ga-PSMA ligand PET/CT-based radiotherapy in locally recurrent and recurrent oligometastatic prostate cancer : early efficacy after primary therapy. Strahlenther Onkol. 2016;192(7):431-9. https://doi.org/10.1007/s00066-016-0982-z.

17. Zschaeck S, Wust P, Beck M, Wlodarczyk W, Kaul D, Rogasch J, et al. Intermediate-term outcome after PSMA-PET guided highdose radiotherapy of recurrent high-risk prostate cancer patients. Radiat Oncol. 2017;12(1):140. https://doi.org/10.1186/s13014017-0877-x.

18. Steuber T, Jilg C, Tennstedt P, De Bruycker A, Tilki D, Decaestecker K, et al. Standard of care versus metastases-directed therapy for PET-detected nodal oligorecurrent prostate cancer following multimodality treatment: a multi-institutional case-control study. Eur Urol Focus. 2018. https://doi.org/10.1016/j.euf.2018.02. 015 .

19. Siva S, Bressel M, Murphy DG, Shaw M, Chander S, Violet J, et al. Stereotactic abative body radiotherapy (SABR) for oligometastatic prostate cancer: a prospective clinical trial. Eur Urol. 2018;74(4): 455-62. https://doi.org/10.1016/j.eururo.2018.06.004.

20. Schmidt-Hegemann NS, Stief C, Kim TH, Eze C, Kirste S, Strouthos I, et al. Outcome after PSMA PET/CT based salvage radiotherapy in patients with biochemical recurrence after radical prostatectomy: a bi-institutional retrospective analysis. J Nucl Med. 2018. https://doi.org/10.2967/jnumed.118.212563.

21. Tsan DL, Fan KH, Chen YC, Chuang CK, Lee CC, Hong JH. Preradiotherapy PSA level as a predictor for biochemical control in prostate cancer patients receiving radiotherapy after radical prostatectomy. Biom J. 2013;36(2):71-6. https://doi.org/10.4103/23194170.110402 .

22. Rodin D, Drumm M, Clayman R, Buscariollo DL, Galland-Girodet S, Eidelman A, et al. Risk factors for disease progression after postprostatectomy salvage radiation: long-term results of a singleinstitution experience. Clin Genitourin Cancer. 2017. https://doi. org/10.1016/j.clgc.2017.07.026.

23. Wiegel T, Lohm G, Bottke D, Hocht S, Miller K, Siegmann A, et al. Achieving an undetectable PSA after radiotherapy for biochemical progression after radical prostatectomy is an independent predictor of biochemical outcome-results of a retrospective study. Int J Radiat Oncol Biol Phys. 2009;73(4):1009-16. https://doi.org/10. 1016/j.ijrobp.2008.06.1922.

24. Punnen S, Cooperberg MR, D'Amico AV, Karakiewicz PI, Moul JW, Scher HI, et al. Management of biochemical recurrence after primary treatment of prostate cancer: a systematic review of the literature. Eur Urol. 2013;64(6):905-15. https://doi.org/10.1016/j. eururo.2013.05.025.

25. Gandaglia G, Abdollah F, Schiffmann J, Trudeau V, Shariat SF, Kim SP, et al. Distribution of metastatic sites in patients with prostate cancer: a population-based analysis. Prostate. 2014;74(2):210 6. https://doi.org/10.1002/pros.22742.

26. Muacevic A, Kufeld M, Rist C, Wowra B, Stief C, Staehler M. Safety and feasibility of image-guided robotic radiosurgery for patients with limited bone metastases of prostate cancer. Urol Oncol. 2013;31(4):455-60. https://doi.org/10.1016/j.urolonc.2011.02.023.

27. Schwenck J, Olthof SC, Pfannenberg C, Reischl G, Wegener D, Marzec J, et al. Intention to treat analysis of (68)Ga-PSMA and (11)C-choline PET/CT versus CT for prostate cancer recurrences after surgery. J Nucl Med. 2019. https://doi.org/10.2967/jnumed. 118.224543.

28. Perera M, Papa N, Christidis D, Wetherell D, Hofman MS, Murphy DG, et al. Sensitivity, specificity, and predictors of positive (68)Gaprostate-specific membrane antigen positron emission tomography in advanced prostate cancer: a systematic review and meta-analysis. Eur Urol. 2016;70(6):926-37. https://doi.org/10.1016/j.eururo. 2016.06.021.

29. Gandaglia G, Karakiewicz PI, Briganti A, Passoni NM, Schiffmann $\mathrm{J}$, Trudeau $\mathrm{V}$, et al. Impact of the site of metastases on survival in patients with metastatic prostate cancer. Eur Urol. 2015;68(2):32534. https://doi.org/10.1016/j.eururo.2014.07.020.

30. Sweeney CJ, Chen Y-H, Carducci M, Liu G, Jarrard DF, Eisenberger M, et al. Chemohormonal therapy in metastatic hormone-sensitive prostate cancer. N Engl J Med. 2015;373(8): 737-46. https://doi.org/10.1056/NEJMoa1503747.

31. Fizazi K, Tran N, Fein L, Matsubara N, Rodriguez-Antolin A, Alekseev BY, et al. Abiraterone plus prednisone in metastatic, castration-sensitive prostate cancer. N Engl J Med. 2017;377(4): 352-60. https://doi.org/10.1056/NEJMoa1704174.

32. Kroeze SGC, Henkenberens C, Schmidt-Hegemann NS, Vogel MME, Kirste S, Becker J, et al. Prostate-specific membrane antigen positron emission tomography-detected oligorecurrent prostate cancer treated with metastases-directed radiotherapy: role of addition and duration of androgen deprivation. Eur Urol Focus. 2019. https://doi.org/10.1016/j.euf.2019.08.012.

Publisher's note Springer Nature remains neutral with regard to jurisdictional claims in published maps and institutional affiliations. 


\section{Affiliations}

Marco M. E. Vogel ${ }^{1,2}$ (D) - Stephanie G. C. Kroeze ${ }^{3}$ (D) Christoph Henkenberens $^{4}$ (D) Nina-Sophie Schmidt-Hegemann ${ }^{5}$ (D) $\cdot$ Simon Kirste $^{6,7}$ (D) $\cdot$ Jessica Becker ${ }^{8} \cdot$ Irene A. Burger $^{9}$ (D) Thorsten Derlin $^{10}$ (D) Peter Bartenstein ${ }^{11} \cdot$ Michael Mix ${ }^{12}$ (D) $\cdot$ Christian la Fougère ${ }^{13,14,15}$ (D) Matthias Eiber $^{16}$ (D) Hans Christiansen $^{4}$ (D) • Claus Belka ${ }^{5,17}$ (D) $\cdot$ Anca L. Grosu ${ }^{6,7}$ (D) Arndt-Christian Müller ${ }^{8}$ (D) Matthias Guckenberger $^{3}$ (D) Stephanie E. Combs ${ }^{1,2,17}$

1 Department of Radiation Oncology, Klinikum rechts der Isar, Technical University of Munich (TUM), Ismaninger Strasse 22, 81675 Munich, Germany

2 Department of Radiation Sciences (DRS), Institute for Radiation Medicine (IRM), Helmholtz Zentrum München, Neuherberg, Germany

3 Department of Radiation Oncology, University Hospital Zurich, University of Zurich, Zurich, Switzerland

4 Department of Radiotherapy and Special Oncology, Medical School Hannover, Hannover, Germany

5 Department of Radiation Oncology, University Hospital LMU Munich, Munich, Germany

6 Department of Radiation Oncology, Medical Center University of Freiburg, Faculty of Medicine, University of Freiburg, Freiburg, Germany

7 German Cancer Consortium (DKTK), Partner Site Freiburg, Freiburg, Germany

8 Department of Radiation Oncology, University Hospital Tübingen, Eberhard Karls University Tübingen, Tübingen, Germany

9 Department of Nuclear Medicine, University Hospital Zurich, University of Zurich, Zurich, Switzerland
10 Department of Nuclear Medicine, Hannover Medical School, Hannover, Germany

11 Department of Nuclear Medicine, University Hospital LMU Munich, Munich, Germany

12 Department of Nuclear Medicine, Medical Center University of Freiburg, Faculty of Medicine, University of Freiburg, Freiburg, Germany

13 Department of Nuclear Medicine and Clinical Molecular Imaging, University Hospital Tübingen, Eberhard Karls University Tübingen, Tübingen, Germany

14 German Cancer Consortium (DKTK), Partner Site Tübingen, Tübingen, Germany

15 Cluster of Excellence iFIT (EXC 2180) "Image Guided and Functionally Instructed Tumor Therapies", University of Tübingen, Tübingen, Germany

16 Department of Nuclear Medicine, Klinikum rechts der Isar, Technical University of Munich (TUM), Munich, Germany

17 German Cancer Consortium (DKTK), Partner Site Munich, Munich, Germany 